\title{
Surgical Outcomes of Unilateral Marcus Gunn Jaw Winking Ptosis Correction: A Novel Whitnall's Ligament Approach
}

\author{
Salil Kumar Mandal, Purban Ganguly, Suman Lodh \\ Department of Orbit \& Oculoplasty and Reconstructive Surgery, Regional Institute of Ophthalmology, Medical College and Hospital, \\ Calcutta, India
}

Purpose: To evaluate the surgical, functional, and cosmetic outcome in moderate to severe ptosis with Marcus Gunn jaw winking phenomenon and recurrence of disease after ptosis correction. This procedure has been emphasized on a child.

Methods: This was a prospective, non-comparative, interventional study conducted over 4 years on 30 people. The ages range from 7 to 40 years. The eyelid was approached from behind to identify the Whitnall's ligament. Levator palpebrae superioris was first disinserted then dissected up to the superior border of the tarsal plate followed by 20 to $25 \mathrm{~mm}$ by resection which causes disabling of the levator palpebrae superioris action. Subsequently, "tarso frontalis sling with silicon rod" for ptosis correction. Compared with the preoperative and postoperative photograph.

Results: Margin reflex distance 1 values are in the affected eye preoperative $1.8 \pm 0.87 \mathrm{~mm}$ to postoperative $3.96 \pm 0.41 \mathrm{~mm}$. Preoperative palpebral fissure height are means $5.05 \pm 0.62 \mathrm{~mm}$ to postoperative palpebral fissure height means $9.3 \pm 0.71$ $\mathrm{mm}$. Ptosis significantly improved which is statistically significant $(p<0.05)$. Lid excursion or Flickering's in affected eyes preoperative means $6.1 \pm 3.47 \mathrm{~mm}$ to postoperative after 1 year means are $0.43 \pm 0.81 \mathrm{~mm}$. Follow-up period is 1 year.

Conclusions: Unilateral posterior approach (Whitnall's ligament approach) is found better in surgical, functional, and cosmetic outcomes in the correction of Marcus Gunn jaw winking syndrome, especially in children. The risk of bilateral extensive surgery is avoided. After the surgery, the primary gaze face photo identity was well-accepted in official government documents. This study is stressed on bilateral lid height similarity in primary gaze unlike the traditional method of downgaze similarities.

The patients were highly satisfied both physically and mentally.

Key Words: Blepharoptosis, Blinking, Marcus Gunn phenomenon

In ptosis, the upper eyelid drops lower than the normal position in primary gaze. In severe ptosis upper lid may

Received: August 26, 2020 Final revision: September 24, 2020

Accepted: November 2, 2020

Corresponding Author: Salil Kumar Mandal, MD. Department of Orbit \& Oculoplasty and Reconstructive Surgery, Regional Institute of Ophthalmology, Medical College and Hospital, 183, R. N. Guha Road, Dumdum, Calcutta, West Bengal 700074, India. Tel: 91-8617266703, Fax: 919433087396, E-mail: salil_dum@live.com drop below the pupilary plane and cover the pupil partially or completely which may cause visual obstruction. Especially in children, this constant visual deprivation leads to the development of the amblyopia. The congenital blepharoptosis cases are almost $50 \%[1,2]$.

In 1883, a peculiar congenital ptosis associated with the winking motion of the upper eyelid was observed by Robert Marcus Gunn. It was a 15-year-old girl. This synkinetic jaw winking phenomenon is now known as Marcus Gunn 
jaw winking syndrome (MGJWS) [3,4].

This study aims to determine the surgical, functional, and cosmetic outcomes in cases of moderate to severe MGJWS corrected by the Novel unilateral posterior approach (Whitnall's ligament approach) and to evaluate the recurrence of the disease.

\section{Materials and Methods}

This was a prospective, non-comparative, interventional, and clinical study of 30 patients over 4 years. Ethical committee approved this study (MC/KOL/IEC/Non-spon/405/ 11-2016). The informed consent was taken from each patient participated in this study and this study conformed to the Declaration of Helsinki. In this study inclusion criteria were moderate to severe MGJWS, ages 7 to 40 years, unilateral ptosis, good bell's phenomenon, patients who gave valid written consent for surgery. The exclusion criteria were MGJWS with mild jaw winking ptosis which is not causing any cosmetic blemish to the patient, poor bell's phenomenon, gross squint/deviation (vertical), corneal anesthesia, myasthenia gravis. Excursion of the ptotic eyelid with jaw movement in MGJWS was graded as mild $(<2$ $\mathrm{mm})$, moderate $(2-5 \mathrm{~mm})$, and severe $(\geq 5 \mathrm{~mm})$ and jaw winking was measured with a millimeter ruler. In this study evaluation parameters were pre and postoperative photograph for documentation, status of bell's phenomenon, preoperative and postoperative vertical palpebral fis-
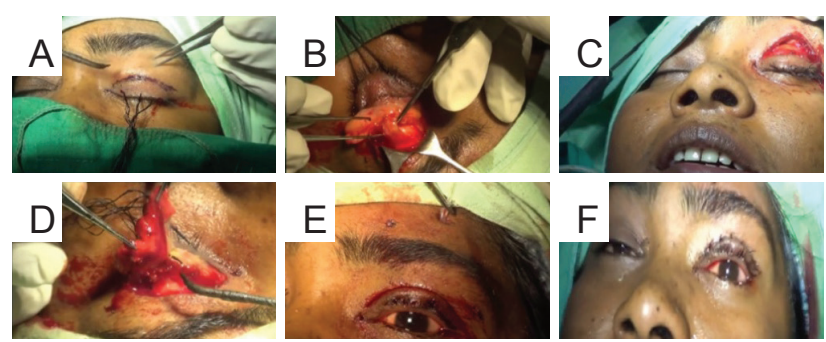

Fig. 1. Steps of surgical procedure of Marcus Gunn jaw winking ptosis correction. (A) Upper lid crease incision made 6 to $7 \mathrm{~mm}$ from the upper border of the lid match to the opposite site. (B) Levator palpebrae superioris is lifted from the underling conjunctiva by lens hook dissected up to the superior border of tarsal plate. (C) Supratarsal skin, muscle complex is intact for silicon rod anchoring. (D) Stretched levator palpebrae superioris excised at the upper border of tarsal plate. (E) Fox pentagon procedure with silicon rod. (F) Wound repair with 5-0 black silk. Written informed consent was obtained from the patients for publication of the clinical images. sure height (PFH), margin reflex distance 1 (MRD-1), preoperative and postoperative eyelid closure, and patient's mental satisfaction. Collected data of 30 study subjects were checked for consistency and completeness; it was then entered in the Microsoft Excel data sheet (Microsoft Corporation, Redmond, WA, USA). Categorical data were expressed in proportions. Paired $t$-test was applied to test the significance. A $p$-value less than $<0.05$ was considered as significant value.

In this study, all the cases were operated single-handedly by an experienced surgeon. In this study, the Novel surgical procedure was applied by the posterior approach (Whitnall's ligament approach). A lid crease incision was made 6 to $7 \mathrm{~mm}$ from the upper lid border to match the opposite upper lid; preseptal muscle and orbital septum were incised in the same line (Fig. 1A). The levator palpebrae superioris (LPS) was identified and dissected upwards to expose the glistening Whitnall's ligament. Here, the muscle hook was passed below the LPS and hooked up to separate it from the conjunctiva (Fig. 1B). It was then disinserted from the ligament and reflected towards the tarsal plate and carefully dissected from the conjunctiva. We observe this approach for the last 4 years that LPS aponeurosis was quite thicker near to Whitnall's ligament rather than near to tarsal plate and easy to separate from the conjunctiva that was a new observation and the newer posterior approach (Whitnall's ligament approach) was tried. Both the medial and lateral horns were dissected meticulously and the bulk of LPS reflected up to the superior border of the tarsal plate; 20 to $25 \mathrm{~mm}$ of LPS was excised and removed so as not to disturb the supratarsal plate skin muscle complex. Here LPS action was totally disabled (Fig. 1C, 1D). Silicon rod was used for fox pentagon tarso frontalis sling procedure which anchors over supratarsal plate. Thus, the skin muscle complex remains undisturbed. It was done for better lifting and anchoring for ptosis correction. There was no suture required for fixation of silicon rod (Fig. 1E) The wound was closed layer by layer (Fig. 1F) Then frost suture was applied for 2 to 4 days. All adult patients had undergone the surgical correction under the Frontal block for the convenience of per-operative evaluation of LPS dissection by jaw movement on command. General anesthesia was introduced to children below 12 years as they wouldn't be able to obey the commands. 
Table 1. Shows age, sex, site, visual acuity vertical central palpebral aperture, MRD-1 preop and postop, flickering preop and postop values

\begin{tabular}{|c|c|c|c|c|c|c|c|c|c|c|c|}
\hline $\begin{array}{c}\text { Patient } \\
\text { no. }\end{array}$ & $\begin{array}{l}\text { Age } \\
(\mathrm{yr})\end{array}$ & $\begin{array}{l}\text { Age } \\
\text { group } \\
(y r)\end{array}$ & Sex & $\begin{array}{l}\text { Visual } \\
\text { acuity } \\
\text { OD by } \\
\text { logMAR } \\
\text { chart }\end{array}$ & $\begin{array}{l}\text { Visual } \\
\text { acuity } \\
\text { OS }\end{array}$ & $\begin{array}{c}\text { Preop } \\
\text { vertical } \\
\text { central } \\
\text { palpebral } \\
\text { aperture } \\
\text { affected } \\
\text { eye }\end{array}$ & $\begin{array}{l}\text { Postop } \\
\text { vertical } \\
\text { central } \\
\text { palpebral } \\
\text { aperture. } \\
\text { affected } \\
\text { eye at } 1 \mathrm{yr}\end{array}$ & $\begin{array}{l}\text { MRD-1 } \\
\text { preop } \\
\text { affected } \\
\text { eye }\end{array}$ & $\begin{array}{l}\text { MRD-1 } \\
\text { postop } \\
\text { affected } \\
\text { eye after } \\
1 \mathrm{yr}\end{array}$ & $\begin{array}{l}\text { Flickering } \\
(\mathrm{mm}) \text { preop } \\
\text { affected eye }\end{array}$ & $\begin{array}{l}\text { Flickering }{ }^{*} \\
\text { (mm) postop } \\
\text { affected eye } \\
\text { after } 1 \mathrm{yr}\end{array}$ \\
\hline 1 & 8 & $<10$ & $\mathrm{~F}$ & 0 & 0 & 5 & 9 & 2 & 3.5 & 4 & 0 \\
\hline 2 & 9 & $<10$ & $\mathrm{~F}$ & 0 & 0 & 5 & 11 & 2 & 4 & 4 & 0 \\
\hline 3 & 24 & $>20$ & $\mathrm{~F}$ & 0 & 0 & 5 & 9 & 2 & 4 & 4 & 0 \\
\hline 4 & 19 & $10-20$ & $\mathrm{~F}$ & 0 & 0 & 4 & 10 & 0 & 3 & 3 & 2 \\
\hline 5 & 24 & $>20$ & $\mathrm{~F}$ & 0 & 0 & 4.5 & 9 & 2 & 4 & 4 & 0 \\
\hline 6 & 12 & $10-20$ & $\mathrm{~F}$ & 0 & 0 & 4 & 10 & 0 & 4 & 4 & 0 \\
\hline 7 & 25 & $>20$ & $\mathrm{~F}$ & 0 & 0 & 5 & 9 & 2 & 4.5 & 3 & 0 \\
\hline 8 & 10 & $10-20$ & $\mathrm{M}$ & 0 & 0 & 4 & 8.5 & 2 & 4 & 4 & 0 \\
\hline 9 & 21 & $>20$ & $\mathrm{~F}$ & 0 & 0 & 5 & 9 & 2 & 4 & 4 & 0 \\
\hline 10 & 40 & $>20$ & $\mathrm{~F}$ & 0.47 & 0.30 & 4 & 8.5 & 0 & 4 & 4 & 0 \\
\hline 11 & 12 & $10-20$ & M & 0 & 0 & 4.5 & 8 & 2 & 3.5 & 3 & 0 \\
\hline 12 & 13 & $10-20$ & $\mathrm{f}$ & 0 & 0 & 5 & 8 & 2 & 4.5 & 13 & 2 \\
\hline 13 & 19 & $10-20$ & $\mathrm{M}$ & 0 & 0 & 6 & 10 & 2 & 4 & 10 & 0 \\
\hline 14 & 20 & $10-20$ & $\mathrm{~F}$ & 0 & 0 & 5 & 10 & 2 & 4.5 & 14 & 0 \\
\hline 15 & 24 & $>20$ & M & 0 & 0 & 4.5 & 10.5 & 2 & 4 & 10 & 0 \\
\hline 16 & 30 & $>20$ & $\mathrm{~F}$ & 0 & 0 & 5 & 9 & 2 & 4 & 12 & 1 \\
\hline 17 & 14 & $10-20$ & $\mathrm{M}$ & 0 & 0 & 6 & 9 & 3 & 4 & 9 & 0 \\
\hline 18 & 8 & $<10$ & $\mathrm{~F}$ & 0 & 0 & 5 & 9 & 3 & 4 & 12 & 0 \\
\hline 19 & 9 & $<10$ & $\mathrm{~F}$ & 0 & 0 & 6 & 9 & 3 & 4 & 3 & 1 \\
\hline 20 & 24 & $>20$ & $\mathrm{~F}$ & 0 & 0 & 5 & 10 & 2 & 4 & 4 & 0 \\
\hline 21 & 19 & $10-20$ & $\mathrm{~F}$ & 0 & 0 & 4.5 & 9 & 2 & 4.5 & 3 & 0 \\
\hline 22 & 24 & $>20$ & $\mathrm{f}$ & 0 & 0 & 4.5 & 10 & 0 & 4 & 4 & 0 \\
\hline 23 & 12 & $10-20$ & M & 0 & 0 & 4.5 & 9 & 2 & 3 & 6 & 0 \\
\hline 24 & 25 & $>20$ & $\mathrm{~F}$ & 0.30 & 0.30 & 5 & 9 & 2 & 4 & 4 & 0 \\
\hline 25 & 10 & $10-20$ & $\mathrm{~F}$ & 0 & 0 & 4 & 10 & 2 & 3 & 10 & 0 \\
\hline 26 & 21 & $>20$ & $\mathrm{~F}$ & 0 & 0 & 5 & 9 & 2 & 4 & 4 & 3 \\
\hline 27 & 40 & $>20$ & $\mathrm{M}$ & 0 & 0 & 4 & 10 & 2.5 & 4.5 & 8 & 0 \\
\hline 28 & 12 & $10-20$ & $\mathrm{~F}$ & 0 & 0 & 4 & 9 & 0 & 4.5 & 4 & 2 \\
\hline 29 & 13 & $10-20$ & $\mathrm{M}$ & 0 & 0 & 5 & 10 & 2.5 & 4 & 8 & 0 \\
\hline 30 & 19 & $10--20$ & $\mathrm{M}$ & 0 & 0 & 4 & 9 & 2 & 4 & 4 & 0 \\
\hline
\end{tabular}

MRD-1 = marginal reflex distance 1; preop = preoperative; postop = postoperative; $\mathrm{OD}=$ right eye; $\log \mathrm{MAR}=\operatorname{logarithm}$ of minimal angle of resolution; OS = left eye.

"Momentery upword excursion. 


\section{Results}

The study was conducted upon 30 patients with moderate to severe MGJWS (Fig. 2A, 2B). The mean age of the study subjects was $18.32( \pm 9.5)$ years and the majority were females $(70 \%)$ (Table 1). In this unilateral study subjects, 19 patients were involved in right eye and 11 patients were in left eyes. Both the study subjects combined to make a single affected eye, which was categorically expressed in the data sheet and compared with unaffected or normal eye. Preoperative vertical PFH in affected eye means were $5.05 \pm 0.62 \mathrm{~mm}$ in compared to postoperative PFH means were $9.31 \pm 071$. The $p$-value was statistically significant ( $p$ $<0.50, t=21.9)$ and in unaffected eye PFH was $10 \mathrm{~mm}$ (Table 2 and Fig. 1). Preoperative MRD-1 mean values in affected eye were $1.8 \pm 0.87 \mathrm{~mm}$ in compared with postoperative MRD-1 in affected eyes were $3.96 \pm 0.41 \mathrm{~mm}$, and in unaffected eye it was $4 \mathrm{~mm}$ (Table 2 and Fig. 2). This was also statically significant ( $p<0.00, t=13.57$ ). This value signifies the good correction of ptosis. Preoperative flickering in the affected eye mean values were $6.12 \pm 3.47$ $\mathrm{mm}$ in compared with postoperative means flickering in affected eye were $0.43 \pm 0.89 \mathrm{~mm}$, and in unaffected eye it was ( 0 ) no flickering ( $p<0.00, t=-8.8$ ) (Table 2 and Fig. 3A, 3B). The values of mean vertical PFH, mean MRD-1,

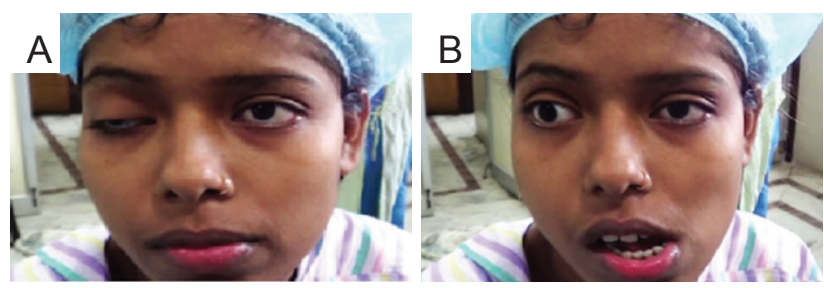

Fig. 2. Preoperative image of patient with Marcus Gunn jaw winking syndrome. (A) Showing preoperative jaw winking phenomenon with jaw movement. (B) Showing preoperative jaw winking phenomenon with jaw movement. Wriiten informed consent was obtained from the patient for publication of these clinical images. and means flickering during follow up period in the 1st month, after 6 months and at the end of 1 year were analysed and also found to be statistically significant when compared with the unaffected eye throughout the follow-up period and difference is less than $1 \mathrm{~mm}$ in all the category. It is cosmetically acceptable.

\section{Discussion}

It is well known that MGJWS is a variant of a congenital ptosis complicated with the abnormal winking motion of the affected lid with jaw movements. MGJWS is usually unilateral. It can occur bilaterally in some rare cases [5]. The wink reflex is the momentary flickering movement of the ipsilateral upper lid, elevation followed by retraction to an equal or higher level in primary gaze. This aberrant stimulation causes contraction of ipsilateral pterygoid, masseter, and sometimes temporalis muscle. This phenomenon is followed by a quick return to a lower position. The wink phenomenon may be elicited by the opening of the mouth, thrusting the jaw to the contralateral side, jaw protrusion, chewing, smiling, or sucking [6,7]. Jaw winking ptosis is mostly sporadic, but familial cases with an irregular autosomal dominant inheritance pattern have been reported [8-10]. An aberrant connection appears to exist be-
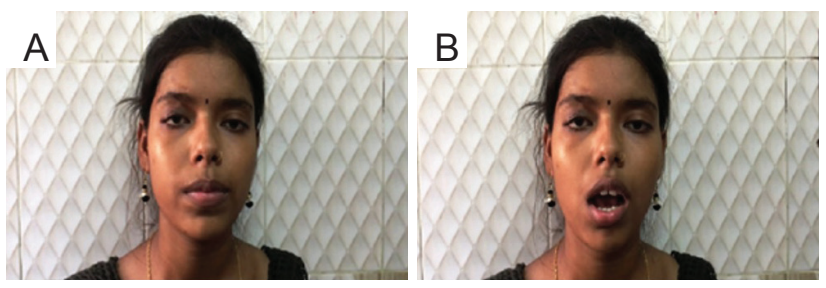

Fig. 3. Postoperative image of patient with Marcus Gunn jaw winking syndrome. (A) Showing postoperative no jaw winking phenomenon with the movement of the jaw. (B) Showing postoperative no jaw winking phenomenon with jaw movement. Wriiten informed consent was obtained from the patient for publication of these clinical images.

Table 2. Showing the mean preoperative and postoperative parameters among the study population $(n=30)$

\begin{tabular}{lcccc}
\hline Parameter & $\begin{array}{c}\text { Mean preoperative } \\
\text { data affected eye }(\mathrm{mm})\end{array}$ & $\begin{array}{c}\text { Mean 1 year } \\
\text { postoperative } \\
\text { data affected eye (mm) }\end{array}$ & $\begin{array}{c}\text { Unaffected } \\
\text { eye }(\mathrm{mm})\end{array}$ & $\begin{array}{c}p \text {-value } \\
\text { Mean vertical palpebral fissure height }\end{array}$ \\
Margin reflex distance 1 & $5.05 \pm 0.62$ & $9.3 \pm 0.71$ & 10 & $<0.00$ \\
Flickering & $1.8 \pm 0.87$ & $3.96 \pm 0.41$ & 4 & $<0.00$ \\
\hline
\end{tabular}




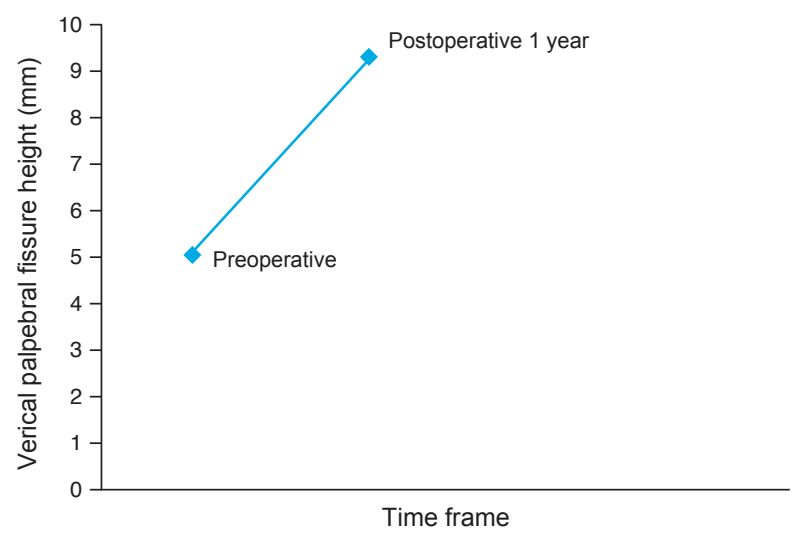

Fig. 4. Showing the comparison of preoperative and postoperative vertical palpebral fissure height among the study population (n $=30$ ).

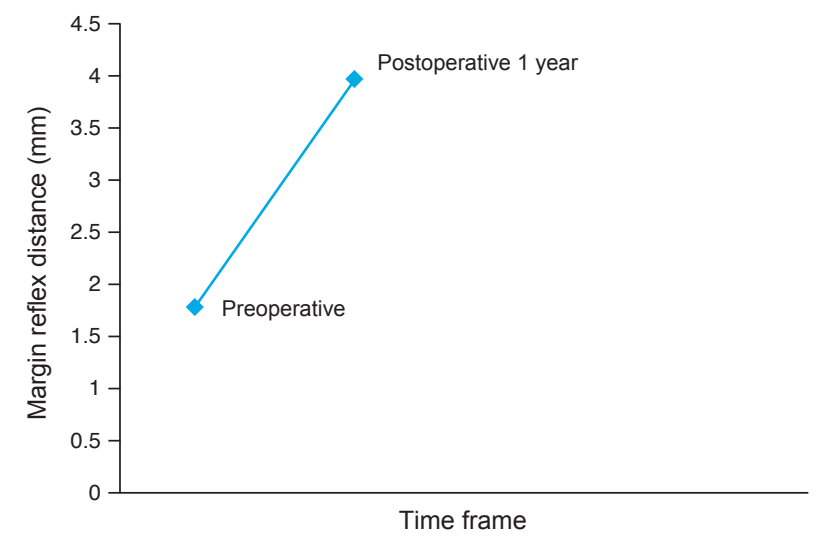

Fig. 5. Showing the comparison of preoperative and postoperative margin reflex distance 1 among the study population $(n=30)$.

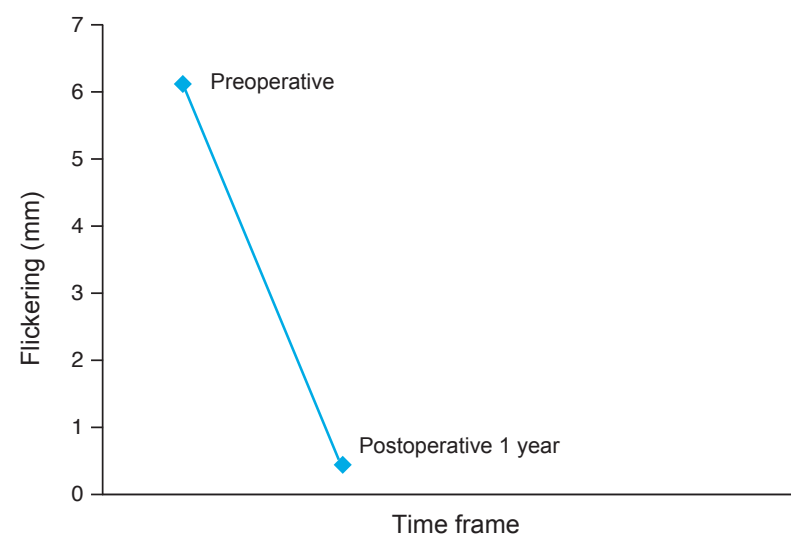

Fig. 6. Showing the comparison of preoperative and postoperative flickering among the study population $(\mathrm{n}=30)$. tween the motor branches of the trigeminal nerve innervating the external pterygoid muscle and the fibers of the superior division of the oculomotor nerve that innervate the LPS muscle of the upper eyelid [11,12]. In jaw winking ptosis levator muscle is abnormally innervated but there is no such secondary myopathic changes. This has been documented histopathologically by previous study $[13,14]$. According to few authors that jaw winking is not due to aberrant pathway it is rather due to disinhibition of primitive phylogenetic mechanisms $[15,16]$. Five percent of the study populations are included in MGJWS. Management depends on the cosmetic significance of the jaw winking. In a case with significant jaw winking, bilateral levator excision with a fascialata, frontalis sling surgery is the established operation of choice. If an attempt is made to repair the ptosis without correcting the jaw winking, it would result in an exaggeration of the aberrant eyelid movement which would be cosmetically unacceptable to the patient. The study was conducted with participants of higher age and the mean was recorded to be $18.32 \pm 9.5$ years (Table 1). A similar study was conducted where the mean age of the patient was reported to be 11.12 years (range, 5 to 19 years). There was a predominance of females in the present study (Table 1). However, unlike our finding, Pratt et al. [1] and Khwarg et al. [3] reported equal prevalence among males and females and a few other studies reported a higher proportion of male involvement in this disease [17-19]. We performed the cases by a Novel surgical approach that is the posterior, approach or Whitnall's ligament approach (Fig. 1). The success rate was found to improve dramatically, especially in children. In the first step of the surgical intervention, LPS muscle is dragged 1 to $2 \mathrm{~mm}$ below the Whitnall's ligament and then disinserted from it. Then LPS is meticulously dissected from the conjunctiva and reflected upto the superior border of tarsal plate (Fig. 1D). Ultimately, about 20 to $25 \mathrm{~mm}$ of LPS aponeurosis is resected. In the second step of the surgical intervention ptosis correction was done by tarso frontalis sling using a silicone rod (Fig. 1E). These two surgical steps were performed in a single sitting, by a single surgeon to shorten the duration of surgical time, and it was noted that the physical comfort and mental satisfaction of the patient in the post-operative period were much higher. In the earlier approaches, the LPS aponeurosis was disinserted and then dissected from the superior border of Tarsal plate. But it was found that dissecting LPS aponeu- 
rosis anteriorly from the tarsal plate is surgically difficult because there the already thinned out LPS fibers are intimately adhered to the conjunctiva. This anterior approach of LPS dissection may lead to conjunctival damage as well as incomplete disinsertion of all LPS attachments. The chances of missing fibers with the earlier anterior approach were found particularly more in the pediatric age group below 12 years, where the command of jaw movements intraoperatively was not possible. So the risk of recurrence of wink reflex is more in anterior approach where dissection commencement from tarsal plate to Whitnall's ligament. But in our study, we observed that LPS was bulky near to Whitnall's ligament and cleavage plane between LPS and the conjunctiva was much easier to find out rather than near superior tarsal plate region. The chances of missing fibers were less and there was no recurrence in our study, especially in the pediatric age group. Some authors suggested that levator excision followed by tarso frontalis in two steps, but didn't mention the approach and allowed the wound for complete healing to prevent reattachment. In the two patients which the authors had operated with two stage intervention 8 weeks apart, both patients were found to have a recurrence of jaw winking [20-22].

Probable explanation is the only disinsertion or inadequate dissection, and incomplete removal of LPS may cause recurrence. This is due to a FOX L2 gene, which helps in the synthesis of protein and formation of the lid. This gene is constantly generating the signal to revert back to default lid condition. Beard suggested that both the steps of surgery should be done together. Bullock [5] suggested the removal of LPS aponeurosis and muscle up to the apex of the orbit. But it is the extensive surgery and an almost inevitable risk of damaging the superior orbit structures. In this study the PFH in affected eyes preoperative mean was $5.05 \pm 0.62 \mathrm{~mm}$ as compared to a postoperative mean of $9.31 \pm 0.71 \mathrm{~mm}$ (Fig. 4). After the surgical correction the mean PFH has remarkably improved which was statistically significant ( $p<0.50, t=26.2$ ) (Table 2 and Fig. 1). When we are comparing the preoperative MRD-1 with postoperative MRD-1 in the affected eyes on day 7th, after 1 month, after 6 months, and after 1 year, it was observed that the means of the MRD-1 were significantly higher in the postoperative period $(3.96 \pm 0.41 \mathrm{~mm})$ than in the preoperative period $(1.81 \pm 0.87 \mathrm{~mm})$ (Fig. 5). Therefore, the present study has found significant correction of ptosis after surgery in the involved eye. The difference was found to be statistically significant ( $p<0.00, t=11.3$ ) (Table 2 and Fig. 2). Khwarg et al. [3] documented the outcome of 24 patients with moderate to severe jaw winking who had undergone frontalis sling suspension operation with autogenous fascialata. In the first group comprising of five patients, bilateral frontalis suspension and levator excision was done. Two patients (40\%) had good outcomes with MRD-1 in both upper eyelids were $3 \mathrm{~mm}$ or more and less with bilateral asymmetry between the MRD-1 of two upper eyelids less than $1 \mathrm{~mm}$. The rest of the 19 patients who underwent bilateral levator excision, results were satisfactory in $13(68.4 \%)$ and moderate in $6(31.6 \%$, between good and poor) patients. Kemp and MacAndie [16] reported the documented results of ptosis repair with brow suspension using mersilene mesh, three patients with MGJWS had poor results. This novel posterior approach (Whitnall's ligament approach) significantly improves momentary flickering movement of upper lid in MGJWS. The present study has found that the mean flickering in the involved eye at the postoperative period of the day 7, 1 month, 6 months, and at 1 year were lesser than the mean flickering of the same studied eye during preoperative period (Fig. 6). Those differences were found to be statistically significant; $p=0.00(p<0.05, t=-8.8)$ (Table 2 and Fig. 3). In surgeries done by Khwarg et al. [3], a total of 27 eyelids exhibiting jaw winking, 10 eyelids (37.0\%) showed complete resolution of jaw winking, and 13 eyelids (48.2\%) showed mild winking postoperatively which was not consistent with our study finding. In another study conducted by Cates and Tyers [23], 14 cases had persistent postoperative jaw winking with conventional levator resection. The authors opined that unless levator muscle is excised well from posterior approach, the surgical outcome will not be satisfactory. Bowyer and Sullivan [11] performed unilateral upper eyelid retractor surgery in patients with mild degree of jaw winking and ptosis. Where as in patients having moderate to severe winking and ptosis, the authors performed bilateral levator weakening surgery with brow suspension. The authors showed that the surgical outcomes were good in both the groups. Tian et al. [12] in 2007 also performed a unilateral levator excision and frontal flaps suspension with best correction in $26(87 \%)$ of 30 patients, moderate results in three $(10 \%)$ patients. Our goal is the Novel unilateral posterior approach (Whitnall's ligament approach) where surgical intervention is up to the superior border of the tarsal plate and does not disturb supra tarsal skin, mus- 
cle complex where the silicon rod is introduced utilizing a fox pentagon procedure for ptosis correction. It is the chief anchoring system and maintains the lid couture as well. Due to minimal surgical manipulation, postoperative lid edema is less and quick rehabilitation of the lid is achieved. There are no chances of slippage of the silicon rod. Revision surgery and re-fixation of silicon rod for ptosis correction is not required. Some authors are performed the anterior approach that is removal of the LPS from the tarsal plate to disable LPS action followed by fascia lata for ptosis correction. The success rate in pediatric age group is not satisfactory [21,24]. Moreover, in recent days fascialata has some disadvantages, e.g., persistent scar on the leg, second surgical site, cosmetically ugly looking. Even harvesting fascialata has been always difficult; it needs extra skill and instrumentation. Though the material is autogenous, it is rigid compared to the silicon rod. Silicon rod is non-reacting, inert, and elastic material specially designed for ptosis surgery. In the anterior approach, fixation of fascia lata or silicon rod over the tarsal plate after skin incision may cause edema and hemorrhage after extensive surgery. It may cause bulky upper lid and difficult to elevate and adjust the lid height perioperatively. There may be suture dehiscence, in fixing the fascialata or silicon rod to the superior surface of the tarsal plate. Often there's slippage of fascia late or non-absorbable sling after direct fixation and as a result of which ptosis recurs [24,25]. Often lid notching has been observed. In the present study, single step minimal surgical manipulation was performed. Our concept of the novel unilateral posterior approach (Whitnall's ligament approach) is valid in most of the cases, parents and patients do not allow operation on healthy and normal eye. In case of any surgical complications in the healthy eye (e.g., eyelid is fixed in downgaze or any lid contour deformity or sling infection) it may need removal of sling or revision surgery. The bilateral approach was always complicated where tissue damage or risk of injury is much higher than a unilateral approach. In this circumstance, there are many difficulties to explain the complications hence it must be avoided. Concerning the aesthetic value or face recognition in the official document photographs, the eye level should be in the primary position of every person and not in the downgaze or up gaze view. Due to the strict standards of our society, the patient might mentally feel pressured and uneasy due to downgaze as it may be rather odd-looking. In this study, we advise every adult patient to maintain their face in primary position for most of the time and avoid down gazing unless it is extremely necessary. Here patient needs slight bent down on the head, lid height is automatically adjusted in downgaze view. Thus, odd looking lid lag is avoided. Some authors suggest unilateral LPS disabling after excision followed by bilateral frontalis sling for better symmetrical lid height in downgaze (e.g., Bowyer and Sullivan [11], Khwarg et al. [3], Callahan [26] modified Beard [9]'s technique chicken beard procedure). Beard [9] suggested bilateral LPS excision with bilateral sling. Their concept was that it would be better to give control to the brow and frontalis muscle over bilateral symmetry of both lid heights. On the contrary, our procedure was much easier for patients and their families/companions to understand than bilateral surgical intervention over the normal eye and its complications $[22,26]$. The surgical outcome of the above-mentioned studies in sync with our study findings has been quite satisfactory. Hence it can be opined that unilateral surgery limited to the ptotic eye lid in patient with MGJWS is quite a viable option.

In conclusion, in this study most of the patients having of MGJWS with moderate to severe jaw winking. In this Novel approach, LPS is disinserted from Whitnall's ligament then excision of LPS about 20 to $25 \mathrm{~mm}$ followed by Fox Pentagon procedure "tarso frontalis sling" with silicon rod for ptosis correction. Overall anatomic, functional and cosmetic outcome is much better documented with pre and postoperative face photograph (Fig. 3). The risk of extensive bilateral surgical procedures is avoided. It is single step short duration surgery. In one year follow up there was no recurrence and the results were cosmetically acceptable to the patients. None of the patients required second surgical intervention. This Novel surgical posterior approach (Whitnall's ligament approach) revolutionized the concept MGJWS surgical correction and enormously improved the success rates.

\section{Conflict of Interest}

No potential conflict of interest relevant to this article was reported. 


\section{Acknowledgements}

I acknowledge all Doctors of Medical College, Calcutta, Department of Ophthalmology, operation theatre, and nursing staff contributed significantly to this study. Last but not the least Professor and Doctor James Christian Fleming and colleague Brain T. Fowler of Hamilton Eye Institution, Memphis, United States of America who inspired me to present this article in ARVO 2020.

\section{References}

1. Pratt SG, Beyer CK, Johnson CC. The Marcus Gunn phenomenon: a review of 71 cases. Ophthalmology 1984;91:2730.

2. Sobel RK, Allen RC. Incidence of bilateral Marcus Gunn jaw-wink. Ophthalmic Plast Reconstr Surg 2014;30:e54-5.

3. Khwarg SI, Tarbet KJ, Dortzbach RK, Lucarelli MJ. Management of moderate-to-severe Marcus-Gunn jaw-winking ptosis. Ophthalmology 1999;106:1191-6.

4. Kirkham TH. Familial Marcus Gunn phenomenon. $\mathrm{Br} J$ Ophthalmol 1969;53:282-3.

5. Bullock JD. Marcus-Gunn jaw-winking ptosis: classification and surgical management. J Pediatr Ophthalmol Strabismus 1980;17:375-9.

6. Demirci H, Frueh BR, Nelson CC. Marcus Gunn jaw-winking synkinesis: clinical features and management. Ophthalmology 2010;117:1447-52.

7. Wong JF, Theriault JF, Bouzouaya C, Codere F. Marcus Gunn jaw-winking phenomenon: a new supplemental test in the preoperative evaluation. Ophthalmic Plast Reconstr Surg 2001;17:412-8.

8. Xiang N, Hu WK, Li B, Liu R. Management of morderate-to-severe Marcus-Gunn syndrome by anastomosis of levator and frontal muscles. Int J Ophthalmol 2010;3:342-5.

9. Beard C. A new treatment for severe unilateral congenital ptosis and for ptosis with jaw-winking. Am J Ophthalmol 1965;59:252-8.

10. Sthapit PR, Saiju R. Surgical outcomes in cases of Marcus-Gunn jaw-winking phenomenon. Kathmandu Univ Med J (KUMJ) 2015;13:34-7.

11. Bowyer JD, Sullivan TJ. Management of Marcus Gunn jaw winking synkinesis. Ophthalmic Plast Reconstr Surg 2004;20:92-8.
12. Tian N, Zheng YX, Zhou SY, et al. Clinical characteristics of moderate and severe Marcus-Gunn jaw-winking synkinesis and its surgical treatment. Zhonghua Yan Ke Za Zhi 2007;43:1069-72.

13. Park DH, Choi WS, Yoon SH. Treatment of the jaw-winking syndrome. Ann Plast Surg 2008;60:404-9.

14. Dillman DB, Anderson RL. Levator myectomy in synkinetic ptosis. Arch Ophthalmol 1984;102:422-3.

15. Koelsch E, Harrington JW. Marcus Gunn jaw-winking synkinesis in a neonate. Mov Disord 2007;22:871-3.

16. Kemp EG, MacAndie K. Mersilene mesh as an alternative to autogenous fascia lata in brow suspension. Ophthalmic Plast Reconstr Surg 2001;17:419-22.

17. Kersten RC, Bernardini FP, Khouri L, et al. Unilateral frontalis sling for the surgical correction of unilateral poor-function ptosis. Ophthalmic Plast Reconstr Surg 2005;21:412-6.

18. Doucet TW, Crawford JS. The quantification, natural course, and surgical results in 57 eyes with Marcus Gunn (jaw-winking) syndrome. Am J Ophthalmol 1981;92:702-7.

19. Spaeth EB. The Marcus Gunn phenomenon; discussion, presentation of four instances and consideration of its surgical correction. Am J Ophthalmol 1947;30:143-58.

20. Betharia SM, Kumar S. Levator sling for Marcus Gunn ptosis. Br J Ophthalmol 1987;71:685-9.

21. Tsai CC, Lin TM, Lai CS, Lin SD. Use of the orbicularis oculi muscle flap for severe Marcus Gunn ptosis. Ann Plast Surg 2002;48:431-4.

22. Putnam JR, Nunery WR, Tanenbaum M, McCord CD Jr. Blepharoptosis. In: McCord CD Jr, Tanenbaum M, Nunery WR, editors. Oculoplastic surgery. 3rd ed. New York: Raven Press; 1995. p. 73-7.

23. Cates CA, Tyers AG. Results of levator excision followed by fascia lata brow suspension in patients with congenital and jaw-winking ptosis. Orbit 2008;27:83-9.

24. Carbajal UM. Surgery of ptosis associated with jaw-winking. Am J Ophthalmol 1959;47:352-7.

25. Bartkowski SB, Zapala J, Wyszynska-Pawelec G, Krzystkowa KM. Marcus Gunn jaw-winking phenomenon: management and results of treatment in 19 patients. $J$ Craniomaxillofac Surg 1999;27:25-9.

26. Callahan A. Correction of unilateral blepharoptosis with bilateral eyelid suspension. Am J Ophthalmol 1972;74:3216. 